Research Article

\title{
Comparison of efficacy of telmisartan with losartan in patients of essential hypertension with cognitive impairment
}

\author{
Nitin Natthuji Puram ${ }^{\text {* }}$, Vitthal Baburao Karande ${ }^{1}$, Jaiprakash Bharma Ramanand ${ }^{1}$, \\ Sunita Jaiprakash Ramanand ${ }^{2}$, Nimish Ravindra Halasawadekar ${ }^{2}$, \\ Rama Rangnathrao Bhosale ${ }^{1}$
}

\begin{abstract}
${ }^{1}$ Department of Pharmacology, RCSM, Government Medical College, Kolhapur, Maharashtra, India,

${ }^{2}$ Department of Pharmacology, Government Medical College, Miraj, Maharashtra, India
\end{abstract}

Received: 06 February 2016 Accepted: 14 March 2016

\section{*Correspondence to: Dr. Nitin Natthuji Puram, Email: drnitinpuram @gmail.com}

Copyright: (C) the author(s), publisher and licensee Medip Academy. This is an openaccess article distributed under the terms of the Creative Commons Attribution NonCommercial License, which permits unrestricted noncommercial use, distribution, and reproduction in any medium, provided the original work is properly cited.

\begin{abstract}
Background: Hypertension can lead to mild to moderate alteration in the brain structure and function including cognitive functions impairments. Many first line antihypertensive drugs are devoid of producing significant improvement in cognitive functions; in fact some of them worsen cognitive function. Data suggests that angiotensin II receptor antagonist slows the progression of cognitive impairment associated with hypertension. Hence present study was planned to compare the efficacy of telmisartan with losartan in hypertensive patients with cognitive impairment.

Methods: Prospective, randomized, single blind, comparative study was conducted for period of 24 weeks. Study population was enrolled into two groups: group A (losartan $50 \mathrm{mg}$ ) and group B (telmisartan $20 \mathrm{mg}$ ). Cognitive functions were assessed by mini mental status examination and trail making test part-A. Qualitative data were analysed by using "Fischer's test" and quantitative data was analysed by using "t test".

Results: Baseline clinical characteristics of patients receiving losartan and telmisartan did not show significant difference Telmisartan was as effective as losartan in lowering systolic and diastolic blood pressure in patients of essential hypertension. Increase in mini mental status examination score appeared similar in both groups and there was no statistically significant difference $(p>0.05)$ between the two groups at 12 and 24 weeks of therapy. Reduction in trail making test part A score was slightly more among patient receiving losartan but on comparison of two groups reduction in trail making test part A score was not statistically significant ( $p>0.05)$ at 12 and 24 weeks of therapy.

Conclusions: Telmisartan is as effective as losartan in controlling blood pressure and improving cognitive function in hypertensive patients with cognitive impairment.
\end{abstract}

Keywords: Cognitive impairment, Mini mental status examination, Losartan, Trail making test-part- A, Telmisartan

\section{INTRODUCTION}

Hypertension is the most common cardiovascular disease. It is well known that hypertension causes damage many of the body organs including the heart, kidney, eyes and brain, and it is the major risk factor for coronary heart disease and stroke. The brain is a major target of the deleterious effect of hypertension. The impact of hypertension on the brain prior to stroke is presently under recognized. Even in asymptomatic hypertensive people, hypertension can lead to mild to moderate alteration in the brain structure and functions including cognitive functions. ${ }^{1}$
Hypertension affects brain in many ways that could explain the link to cognitive impairment. ${ }^{2}$ Hypertension changes the structure of cerebral blood vessels and interfere intrinsic vasoregulatory mechanism that assure an adequate blood supply to the brain. These alterations can lead to decrease in the cerebral blood supply and increase the chances of brain ischaemic injury and disease. $^{3}$ There is an association between impaired cerebrovascular dysfunction and cognitive deficits. ${ }^{4}$

The renin angiotensin system (RAS) in the brain is involved in the systemic blood pressure control, including regulation of cerebral blood flow. Although the blood 
brain barrier is impermeable for all RAS components, a local brain RAS has possible physiological and pharmacological function in the nervous system. Recent evidence suggests that the RAS has main role in linking hypertension to cognitive function offering new therapeutic options for cognitive protection. $^{5}$ Angiotensinogen is converted to angiotensin I which is reduced to angiotensin II by angiotensin converting enzyme. Neurons inside the blood brain barrier, cerebrovascular endothelial cells and circumventricular organs contain angiotensin II and its receptors. Angiotensin II has main role in the pathophysiology of hypertension. It alters the coupling between synaptic activity and cerebral blood flow which is critical homeostatic mechanism that assure adequate cerebral perfusion to brain regions. ${ }^{6}$ In animal models angiotensin II has been associated with impairment of cognitive function. ${ }^{7}$

Owing to the role of RAS in modulating cognitive processes, drug that inhibits angiotensin II actions by blocking angiotensin 1 receptors possesses potential of preventing cognitive decline and even improving cognitive function in hypertensive patients. Telmisartan and losartan inhibit actions of RAS by blocking angiotensin 1 (AT1) receptors.

First line antihypertensive drugs are devoid of any effect on cognitive function. Study states that non selective beta antagonist in fact worsen cognitive function. ${ }^{8}$ Also guidelines for treatment of hypertension with cognitive impairment are not available. Hence an antihypertensive drug with additional beneficial effect on cognitive function would be desirable for the treatment of hypertension with cognitive impairment.

Losartan is a prototype angiotensin receptor blocker (ARB) effective in hypertensive patients. Studies have shown that losartan improves cognitive impairment in mild to moderate hypertensive patients. ${ }^{9,10}$ Telmisartan is most lipophilic agent among ARBs there it readily crosses the blood brain barrier to cause AT1 receptors blockade therefore it might have beneficial effect on cognitive impairment in hypertensive patients. Hence the present study was conducted to compare the efficacy of telmisartan with losartan in patients of essential hypertension with cognitive impairment.

\section{METHODS}

The study was carried out in tertiary care hospital and study protocol was approved by Institutional Ethics Committee. This was prospective, randomized, single blind, comparative clinical study. Patients attending outpatient department of medicine were screened. Fifty one patients were enrolled in this study as per the selection criteria after receiving written informed consent. Patients were randomized to receive either losartan (50 mg once a day) or telmisartan (20 mg once a day). Group A received tablet losartan $50 \mathrm{mg}$ orally once a day for 24 weeks and group B received tablet telmisartan $20 \mathrm{mg}$ orally once a day for 24 weeks. Cognitive functions were tested by Mini mental status examination (MMSE) test and trail making test (TMT) part-A. ${ }^{11,12}$ The following categories of patients were enrolled for the study; newly diagnosed patients with essential hypertension of either sex with age more than 51 years, patients whose MMSE test score between 20-25 and TMT Part- A score $>78$ and patients educated up to $4^{\text {th }}$ standard. The following categories of patients were excluded from the study; patients on other antihypertensive drugs, patients who by clinical judgment required combination antihypertensive treatment, patients with bilateral renal artery stenosis, major psychiatric illness and patients with history of stroke, head injury with loss of consciousness and those who denied to provide consent.

Patients were enrolled after informed and written consent as per inclusion and exclusion criteria. Demographic profile, current medical history, diagnosis and baseline (Day 0) parameters like systolic blood pressure(SBP), diastolic blood pressure(DBP), score of MMSE test and TMT part- A were noted during the first visit. Patients were randomly assigned to receive losartan or telmisartan for 24 weeks of duration. After enrollment into study follow up was done at 4, 8, 12 and 24 weeks of therapy. At each visit clinical examination, SBP and DBP were recorded in sitting position after 10 minutes of rest by using sphygmomanometer apparatus. Cognitive functions were tested before the start of drug therapy and at the end of 12 and 24 weeks of drug therapy of each group. Dose titration was done in patient whose blood pressure was not controlled at 4 weeks.

\section{Statistics}

Qualitative data namely age, gender were analysed by using 'Fischer's test for difference between proportions. Comparison between quantitative data within groups was analysed by paired 't'test. Comparison between quantitative data across groups was analysed by unpaired' test. $\mathrm{p}<0.05$ was taken as significant and $\mathrm{p}<0.0001$ was taken as highly significant.

\section{RESULTS}

Table 1: Demography and baseline characteristics of the study population.

\begin{tabular}{|c|c|c|c|}
\hline Characteristics & $\begin{array}{l}\text { Losartan } \\
\text { group }(n=27)\end{array}$ & $\begin{array}{l}\text { Telmisartan } \\
\text { group }(n=24)\end{array}$ & p value \\
\hline \multicolumn{4}{|l|}{ Age (years) } \\
\hline Mean & $62.41 \pm 6.89$ & $59.46 \pm 6.20$ & $\mathrm{p}=0.1166$ \\
\hline Range & $50-76$ & $51-72$ & \\
\hline \multicolumn{4}{|l|}{ Gender } \\
\hline Male & 19 & 17 & $\mathrm{p}=0.9711$ \\
\hline Female & 8 & 7 & \\
\hline \multicolumn{4}{|c|}{ Blood Pressure(mm of $\mathbf{H g})$} \\
\hline $\begin{array}{ll}\text { SBP } & 1\end{array}$ & $148.52 \pm 9.55$ & $149.17 \pm 12.99$ & $\mathrm{p}=0.8388$ \\
\hline DBP & $94.44 \pm 4.20$ & $97.25 \pm 6.66$ & $\mathrm{p}=0.0750$ \\
\hline \multicolumn{4}{|c|}{ Cognitive functions } \\
\hline MMSE Score & $23.19 \pm 1.01$ & $23.00 \pm 1.04$ & $\mathrm{p}=0.6184$ \\
\hline $\begin{array}{l}\text { TMT part- } \\
\text { A Score }\end{array}$ & $104.41 \pm 13.86$ & $105.42 \pm 22.34$ & $\mathrm{p}=0.8453$ \\
\hline
\end{tabular}

Values are expressed as mean \pm S.D. 
Table 2: Comparison of change in systolic blood pressure in losartan group versus telmisartan group.

\begin{tabular}{|lccc|}
\hline Time & $\begin{array}{l}\text { Losartan } \\
(\mathbf{n}=\mathbf{2 7})\end{array}$ & \multicolumn{2}{c}{ Telmisartan } \\
$(\mathbf{n}=\mathbf{2 4})$ & \multicolumn{2}{c|}{$\begin{array}{l}\text { Change across } \\
\text { groups }\end{array}$} \\
\hline Baseline & $148.52 \pm 9.55$ & $149.17 \pm 12.99$ & $\mathrm{p}=0.8388$ \\
\hline 4 weeks & $133.48 \pm 8.78$ & $137.25 \pm 9.03$ & $\mathrm{p}=0.1377$ \\
\hline 8 weeks & $124.44 \pm 10.20$ & $125.25 \pm 8.80$ & $\mathrm{p}=0.7654$ \\
\hline 12 weeks & $122.30 \pm 8.58$ & $125 \pm 5.14$ & $\mathrm{p}=0.1857$ \\
\hline 24 weeks & $120.07 \pm 7.28$ & $117.42 \pm 7.94$ & $\mathrm{p}=0.2187$ \\
\hline
\end{tabular}

Values are expressed in $\mathrm{mm} \mathrm{Hg}$, mean \pm S.D.

Table 3: Comparison of change in diastolic blood pressure in losartan group versus telmisartan group.

\begin{tabular}{|c|c|c|c|}
\hline Time & $\begin{array}{l}\text { Losartan } \\
(\mathrm{n}=27)\end{array}$ & $\begin{array}{l}\text { Telmisartan } \\
(n=24)\end{array}$ & $\begin{array}{l}\text { Change across } \\
\text { groups }\end{array}$ \\
\hline Baseline & $94.44 \pm 4.20$ & $97.25 \pm 6.66$ & $\mathrm{p}=0.0750$ \\
\hline 4 weeks & $88.30 \pm 7.43$ & $88.83 \pm 6.21$ & $\mathrm{p}=0.7823$ \\
\hline 8 weeks & $82.74 \pm 8.21$ & $80.42 \pm 8.72$ & $\mathrm{p}=0.3321$ \\
\hline 12 weeks & $82.00 \pm 5.23$ & $80.83 \pm 5.83$ & $\mathrm{p}=0.4552$ \\
\hline 24 weeks & $78.37 \pm 5.05$ & $79.33 \pm 6.31$ & $\mathrm{p}=0.5485$ \\
\hline
\end{tabular}

Values are expressed in $\mathrm{mm} \mathrm{Hg}$, mean \pm S.D

Table 4: Comparison of change in mini mental status examination score in losartan group versus telmisartan group.

\begin{tabular}{|llcc|}
\hline Time & $\begin{array}{l}\text { Losartan } \\
(\mathbf{n = 2 7})\end{array}$ & $\begin{array}{l}\text { Telmisartan } \\
(\mathbf{n = 2 4})\end{array}$ & $\begin{array}{l}\text { Change across } \\
\text { groups }\end{array}$ \\
\hline Baseline & $23.19 \pm 1.01$ & $23.04 \pm 1.04$ & $\mathrm{p}=0.6184$ \\
\hline 12 weeks & $24.89 \pm 0.89$ & $25.25 \pm 0.44$ & $\mathrm{p}=0.0786$ \\
\hline 24 weeks & $26.41 \pm 0.63$ & $26.75 \pm 0.60$ & $\mathrm{p}=0.0557$ \\
\hline
\end{tabular}

Values are expressed in mean \pm SD

Table 5: Comparison of change in trail making test part-a score in losartan group versus telmisartan group.

\begin{tabular}{|c|c|c|c|}
\hline Time & $\begin{array}{l}\text { Losartan } \\
(\mathbf{n}=27)\end{array}$ & $\begin{array}{l}\text { Telmisartan } \\
(n=24)\end{array}$ & $\begin{array}{l}\text { Change across } \\
\text { groups }\end{array}$ \\
\hline Baseline & $104.41 \pm 13.86$ & $\begin{array}{ll}6 & 105.42 \pm 22.34\end{array}$ & $\mathrm{p}=0.8453$ \\
\hline 12 weeks & $85.85 \pm 8.87$ & $85.17 \pm 23.78$ & $\mathrm{p}=0.8898$ \\
\hline 24 weeks & $73.41 \pm 8.77$ & $74.38 \pm 15.49$ & $\mathrm{p}=0.7818$ \\
\hline
\end{tabular}

Table 1 shows that study population was predominantly male in the age group of 58-63 years. Baseline clinical characteristics of patients receiving losartan and telmisartan were comparable $(\mathrm{p}>0.05)$.

\section{DISCUSSION}

Hypertension remains the most common, readily identifiable and reversible risk factor for myocardial infarction, stroke, heart failure and other vascular complications. It has been identified as one of the major risk factors for cognitive impairment.
The RAS plays major role in the control of blood pressure and cerebral blood flow. The components of RAS are renin, angiotensinogen, angiotensin converting enzyme, angiotensin peptides and angiotensinases. The major actions of angiotensin II are mediated by angiotensin 1 receptors. Angiotensin converting enzyme inhibitors (ACEIs) decrease synthesis of angiotensin II while ARBs prevent binding of angiotensin II to its receptors. Telmisartan and losartan are ARBs used for treatment of hypertension.

There were 4 dropouts in losartan and 5 dropouts in telmisartan treated group. Reason for dropout from the study was lost to follow up. Patients who completed 24 weeks of therapy have been included for statistical analysis i.e. 27 patients in losartan group and 24 patients in telmisartan group.

In the present study, in losartan group 4 (13\%) patients did not attain blood pressure of $140 / 90 \mathrm{mmHg}$ at 4 weeks. In these patients the dose was titrated to $50 \mathrm{mg}$ twice a day. In telmisartan group, $6(20 \%)$ patients did not attain blood pressure of $140 / 90 \mathrm{~mm}$ of $\mathrm{Hg}$ at 4 week at the dose of $20 \mathrm{mg}$ once a day and the dose was titrated to $40 \mathrm{mg}$ twice a day. Those patients required dose titration at 4 week excluded from the study.

The present study showed that telmisartan is as effective as losartan in lowering systolic and diastolic blood pressure in patients of essential hypertension. There is data to suggest that newer ARBs like telmisartan may be more effective than older ARBs e.g. losartan in hypertension. Zhu JR et al and Mallion J et al showed that telmisartan was more effective than losartan in hypertensive patients. ${ }^{13,14}$

Mini mental status examination test and trail making test part-A are standard test for evaluation of cognitive impairment. An increase in the MMSE score and reduction in TMT part-A score are used as marker of improvement in cognitive function.

In the present study, MMSE test score improved at 12 and 24 weeks for losartan and telmisartan group. MMSE test score as compared to baseline was statistically highly significant $(p<0.0001)$ in both the groups but there was no statistically significant difference $(\mathrm{p}>0.05)$ between two groups at 12 and 24 weeks. TMT part-A score reduced at 12 and 24 weeks in both the losartan and telmisartan group. Reduction of score at 12 and 24 weeks as compared to baseline was statistically highly significant for both the group $(\mathrm{p}<0.0001)$ but there was no statistically significant difference $(p>0.05)$ between two groups at 12 and 24 weeks. This shows that telmisartan is as effective as losartan on impaired cognitive function in hypertensive patients.

Persistent hypertension that results in decrease cerebral blood flow is associated with vascular dementia and results in cognitive decline. Ruitenberg A et al showed 
lower cerebral blood flow associated with progressive decline in cognitive function. ${ }^{15}$ High blood pressure can cause different types of cerebrovascular damage associated with the increase in atherosclerosis in larger vessels and in oxidative stress at the level of vascular wall. ${ }^{16}$ Regional cerebral blood responses during memory process were blunted in parietal and thalamic area among hypertensive adults who compared to normotensive. ${ }^{17}$ This suggested that cerebral blood flow has effect on cognitive function in hypertensive patients. Further, Silvestrini $\mathrm{M}$ et al stated that abnormal cerebrovascular reactivity associated with worsening cognitive decline in patients with Alzheimer's disease. ${ }^{18}$

Chronic activation of brain RAS with sustained production of angiotensin II induces cerebrovascular remodeling, promote vascular inflammation and oxidative stress leading to endothelial impairment and impaired regulation of cerebral blood flow. Therefore ARBs restore cerebral blood flow by inhibiting the actions of angiotensin II on its receptors.

Many studies have shown that ARBs improve cognitive impairment in hypertensive patient. Tedesco et al, showed that losartan significantly improved MMSE test score in patients of mild to moderate hypertension with cognitive impairment. ${ }^{9}$ Study carried out by Fogari R et al, using losartan on memory function in very elderly hypertensive patient showed significant effect on memory test. ${ }^{10}$ In another study carried out by Fogari $\mathrm{R}$ et al, showed beneficial effect of telmisartan along with hydrochlorothiazide on cognitive impairment in hypertensive patients. ${ }^{19}$ The result suggested that losartan and telmisartan were effective in cognitive impairment in hypertensive patients.

However, contradictory findings have been reported. Tchekalarova $\mathbf{J}$ et al showed that direct administration of angiotensin in the brain facilitated the cognitive function. ${ }^{20}$ Bilateral microinjection of angiotensin II in the hippo-campal area of rats improved learning in the shuttle box. ${ }^{21}$ In the $\mathrm{T}$ maze test exploratory activity of rats were increased after administration of angiotensin. ${ }^{22}$ These reports show that angiotensin II has role in the learning and memory process. Hanes DS et al showed that ACE inhibitors and ARBs help to preserve cognitive function through a mechanism that is independent of the antihypertensive effects in humans. ${ }^{23}$ Dominik $W$ et al, showed that telmisartan attenuates cognitive impairment by stimulating peroxisome proliferator -activated receptor $\gamma$ and long term inhibition of angiotensin 1 receptors in rats. $^{24}$

\section{CONCLUSION}

It is concluded that telmisartan is as effective as losartan in controlling blood pressure and improving in cognitive function in hypertensive patients with cognitive impairment. Further studies are required to assess and compare additional mechanisms of losartan and telmisartan in hypertensive patients with cognitive impairment.

Funding: No funding sources

Conflict of interest: None declared

Ethical approval: The study was approved by the Institutional Ethics Committee

\section{REFERENCES}

1. Waldstein SR. The relation of hypertension to cognitive function. Curr Dir Psychol Sci. 2003;12:9-12.

2. Waldstein SR, Katzel LI, Elias MF. Hypertension and cognitive function. Neuropsychology of cardiovascular disease. $1^{\text {st }}$ ed. New York: Psychology press; 2001:15-36.

3. Kelley BJ, Petersen RC. Alzheimer's disease and mild cognitive impairment. Neurol clin. 2007;25:577-609.

4. Kelleher, Rory J, Soiza RL. Evidence of endothelial dysfunction in the development of alzheimer's disease: is alzheimer's a vascular disorder? AMJ Cardiovasc Dis. 2013;3(4):197-226.

5. Ciobica A, Bild W, Hritcu L, Haulica I. Brain reninangiotensin system in cognitive function: pre-clinical findings and implications for prevention and treatment of dementia. Acta Neurol Belg. 2009;109:171-80.

6. Kazama K, Wang G, Frys K, Anrather J, Iadecola C. Angiotensin II attenuates functional hyperemia in the mouse somatosensory cortex. AMJ Physiol. 2003;285:1890-99.

7. Raghavendra V, Chopra K, Kulkarni SK. Involvement of cholinergic system in losartaninduced facilitation of spatial and short-term working memory. Neuropeptides. 1998;32:417-21.

8. Tripathi KD. Antiadrenergic drugs (adrenergic receptor antagonist) and drugs for glaucoma. essential of medical pharmacology. New Delhi. Jaypee brothers Medical Publishers; 2013:140-57.

9. Tedesco MA, Ratti G, Mennella S, Manzo G, Grieco $\mathrm{M}$, Rainone $\mathrm{AC}$, et al. Comparison of losartan and hydrochlorothiazide on cognitive function and quality of life in hypertensive patients. Am J Hypertens. 1999;12:1130-4.

10. Fogari R, Mugellini A, Zoppi A, Derosa G, Pasotti C, Fogari E, et al. Influence of losartan and atenolol on memory function in very elderly hypertensive patient. J Hum Hypertens. 2003;17:781-5.

11. Folstein MF, Folstein SE, McHugh PR. Mini-mental state. A practical method grading the cognitive state of patients for the clinician. J Psychiatr Res. 1975;12(3):189-98.

12. Corrigan JD, Hinkeldey MS. Relationships between parts A and B of the trail making test. J Clin Psychol. 1987;43:402-9.

13. Zhu JR, Bai J, Cai NS. Efficacy and safety of telmisartan versus losartan in control of mild-to- 
moderate hypertension: a multicentre, randomised, double-blind study. Int J Clin Pract. 2004;145:46-9.

14. Mallion J, Siche J, Lacourcière Y. ABPM comparison of the antihypertensive profiles of the selective angiotensin II receptor antagonists telmisartan and losartan in patients with mild-tomoderate hypertension. J Hum Hypertens. 1999;13:657-64.

15. Ruitenberg A, den Heijer T, Bakker SL, van Swieten JC, Koudstaal PJ, Hofman A, et al. Cerebral hypoperfusion and clinical onset of dementia: the Rotterdam study. Ann Neurol. 2005;57:789-94

16. Bodiga VL, Bodiga S. Renin angiotensin system in cognitive function and dementia. Asian Journal of Neuroscience. 2013;2013:1-18.

17. Jennings JR, Muldoon MF, Price J, Christie IC, Meltzer CC. Cerebrovascular support for cognitive processing in hypertensive patients is altered by blood pressure treatment. Hypertension. 2008;52:65-71

18. Silvestrini M, Pasqualetti P, Baruffaldi R, Bartolini M, Handouk Y, Matteis M, et al. Cerebrovascular reactivity and cognition decline in patients with Alzheimer's disease. Stroke. 2006;37:1010-5.

19. Fogari R, Mugellini A, Zoppi A, Lazzari P, Destro M, Rinaldi A, et al. Effect of telmisartan/hydrochlorothiazide versus lisinopril/hydrochlorothiazide combination on ambulatory blood pressure and cognitive function in elderly hypertensive patients. J Hum Hypertens. 2006;20(3):177-85.

20. Tchekalarova j, Pechlivanova D, Kambourova T, Matsoukas J, Georgiev V. The effect of sarmesin, an angiotensin II analogue on seizure susceptibility, memory function and nociception. Regul Pept. 2003;111:191-7.

21. Braszko JJ, Kulakowska A, Polecka WK. CGP 42112A antagonism of the angiotensin II and angiotensin II (3-7) facilitation of recall in rats. Pharmacol Res. 1998;38:461-8.

22. Braszko JJ, Wisneiwski K, Kupryszewski G,Witczuk B. Psychotropic effects of angiotensin II and III in rats: locomotor and exploratory versus cognitive behaviour. Behav Brain Res.1987;25:195-203.

23. Hanes DS, Weir MR. Usefulness of ARBs and ACE inhibitors in the prevention of vascular dementia in the elderly. Am J Geriatr Cardiol. 2007;16(3):175-82.

24. Dominik W, Jan J, Braszko. Telmisartan attenuates cognitive impairment caused by chronic stress in rats. Pharmacological reports. 2014;66:436-41.

Cite this article as: Puram NN, Karande VB, Ramanand JB, Ramanand SJ, Halasawadekar NR, Bhosale RR. Comparison of efficacy of telmisartan with losartan in patients of essential hypertension with cognitive impairment. Int $\mathrm{J}$ Basic Clin Pharmacol 2016;5:702-6. 